Article

\title{
Reduction Strategies for Greenhouse Gas Emissions from High-Speed Railway Station Buildings in a Cold Climate Zone of China
}

\author{
Nan Wang ${ }^{1}\left(\mathbb{D}\right.$, Daniel Satola ${ }^{2}{ }^{\mathbb{D}}$, Aoife Houlihan Wiberg ${ }^{3}$, Conghong Liu ${ }^{1, *}$ and \\ Arild Gustavsen ${ }^{2}$ \\ 1 School of Architecture, Tianjin University, No. 92 Weijin Street, Nankai District, Tianjin 300072, China; \\ nancywang@tju.edu.cn \\ 2 Research Centre of Zero Emission Neighbourhoods in Smart Cities (FME-ZEN), Department of Architecture \\ and Technology, Norwegian University of Science and Technology, 7491 Trondheim, Norway; \\ daniel.satola@ntnu.no (D.S.); arild.gustavsen@ntnu.no (A.G.) \\ 3 Belfast School of Architecture and the Built Environment, Faculty of Computing, Engineering and the Built \\ Environment, Ulster University, Belfast BT15 1ED, UK; a.wiberg@ulster.ac.uk \\ * Correspondence: conghong_liu@163.com
}

Received: 21 January 2020; Accepted: 18 February 2020; Published: 25 February 2020

check for updates

\begin{abstract}
Implementing China's emission reduction regulations requires a design approach that integrates specific architectural and functional properties of railway stations with low greenhouse gas (GHG) emission. This article analyzes life cycle GHG emissions related to materials production, replacement and operational energy use to identify design drivers and reduction strategies implemented in high-speed railway station (HSRS) buildings. A typical middle-sized HSRS building in a cold climate zone in China is studied. A detailed methodology was proposed for the development and assessment of emission reduction strategies through life cycle assessment (LCA), combined with a building information model (BIM). The results reveal that operational emissions contribute the most to total GHG emissions, constituting approximately $81 \%$ while embodied material emissions constitute $19 \%$, with $94 \mathrm{kgCO}_{2 \mathrm{eq}} / \mathrm{m}^{2} \cdot$ a and $22 \mathrm{kgCO} \mathrm{keq}_{2} / \mathrm{m}^{2} \cdot$ a respectively. Optimizing space can reduce operational GHG emissions and service life extension of insulation materials contributes to a $15 \%$ reduction in embodied GHG emissions. In all three scenarios, the reduction potentials of space, envelope, and material type optimization were $28.2 \%, 13.1 \%$, and $3.5 \%$ and that measures for reduced life cycle emissions should focus on space in the early stage of building design. This study addresses the research gap by investigating the life cycle GHG emissions from HSRS buildings and reduction strategies to help influence the design decisions of similar projects and large space public buildings which are critical for emission reduction on a larger scale.
\end{abstract}

Keywords: GHG emissions; life cycle assessment; large space building; high-speed railway station

\section{Introduction}

Globally, the construction and operation of buildings account for 36\% of the total final energy use and nearly $40 \%$ of greenhouse gas (GHG) emissions represented by carbon dioxide $\left(\mathrm{CO}_{2}\right)$ [1] . China's carbon emissions will peak by 2030 and, thus, need to be reduced dramatically as pledged in the Intended Nationally Determined Contribution (INDC), signed as part of the Paris Climate Agreement [2]. As the largest carbon emitter in the world, China is facing severe challenges in saving energy and reducing GHG emissions of built environments, which are gaining in importance as it moves to bring the building sector under control. In the 13th Five-Year Plan (2016-2020) implemented by the State Council, aiming to save energy and cut emissions, public buildings are emphasized [3], 
given that they have the largest share in the total consumption of operational energy (excluding district heating) among the different building categories. The most important reason is that the proportion of large-scale or large space public buildings in the building sector-for instance, transportation buildings - has been rising rapidly [4]. Large space buildings refer to those that have great floor height, large enclosed space volumes, and diverse ventilation systems [5]. Energy consumption of transportation buildings per square metre is two to three times that of conventional public buildings such as offices and schools, indicating their greater impact on energy and environment [6] (see Figure 1). As a typical large space public building, a high-speed railway station (HSRS) building is attracting increasing attention. The operating mileage of high-speed railway in China currently ranks first in the world under the 'eight vertical and eight horizontals' railway network plan [7]. These often run on newly created lines and therefore require improved modern stations on new sites. HSRS, known as the gateway to the city, will gradually become the most common type of railway stations, and an increasing amount of constructions will likely promote an upward trend in energy and resource demand in the immediate future. Due to increasingly stringent energy requirements and improved energy efficiency, the embodied GHG emissions from building materials are gaining significance [8-11]. As a major consumer of societal energy and national resources, it is necessary to conduct evaluative research on HSRS buildings in the scope of embodied GHG emissions.

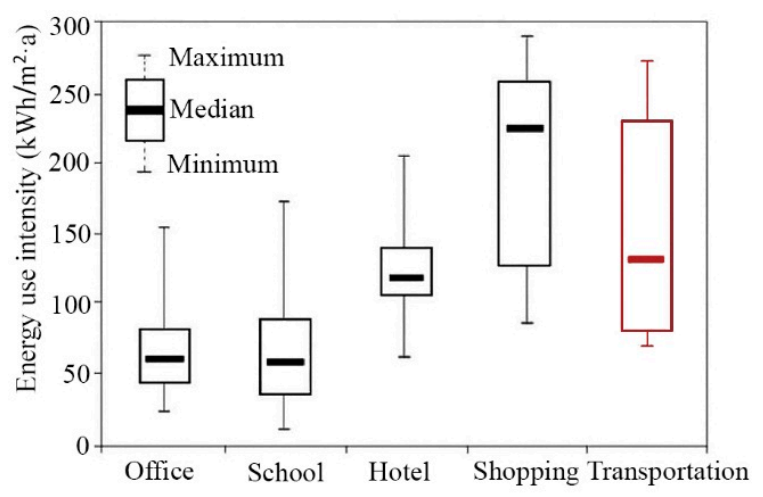

Figure 1. Energy use comparison among five types of public buildings [6].

Several studies have focused on the energy consumption and carbon emissions from multiple building typologies internationally, including residential, office, school, and hotel buildings in China [8,9], Norway [10,11], Spain [12] and the United Kingdom [13]. More attention should be paid to the environmental performance of HSRS buildings, which also needs to be drastically improved. A shift toward low-emission buildings of railway stations is laying down solid tracks for the sustainable building sector. The concepts of 'zero emission station', 'zero energy station', 'green station', and 'eco station' have emerged in order to address the global warming challenges from railway stations: for instance, the European Commission supports sustainable station constructions with the 'Sus Station' project and has achieved a new sustainable, low-carbon generation [14]. The green railway stations rating program of the Indian Green Building Council aims to reduce the adverse environmental impacts due to station operation and maintenance [15]. Despite all of this, earlier studies on railway station buildings mainly focused on energy efficiency [16-22], indoor thermal comfort [23,24], and ventilation and air quality evaluation $[25,26]$. Some research discussed the environmental impacts of the railway transport sector, in which railway stations are usually considered as a part of the whole infrastructure. In rail system studies, Håkan et al. [27] presented the energy use and GHG emissions results from example railway stations in construction, maintenance and operation by a life cycle approach. Zhang et al. [28] calculated high-speed transport energy consumption based on the construction investment integrating elements of life cycle analysis. However, work on the direct perspective of the emission data, as well as design measures in detail, is rather limited. Further study 
is needed to consider life cycle GHG emissions from HSRS buildings, which is rarely studied as the main research object.

Life cycle assessment (LCA) is a well established approach used for the environmental assessment of buildings and provides the necessary information for reducing the environmental impacts systematically and comprehensively [29]. It would be only giving a limited perspective of the environmental impact of a given building to judge the GHG emissions only during its operating phases. LCA makes it possible to evaluate the total GHG emissions and help to determine the ratio between embodied and operational emissions. Furthermore, LCA also aids designers in selecting optimal design solutions, by evaluating different emission reduction measures [30].

The complete life cycle of a building measures the cradle-to-grave impacts from four main stages [31]: the product stage (A1-A3), construction process stage (A4-A5), use stage (B1-B7), and end-of-life stage (C1-C4). The optional stage of benefits and loads (D) is defined to document potential emission compensation of processing or reusing materials after end-of-life. In accordance with international LCA standards [32,33], the LCA methodology is used to quantify the life cycle GHG emissions following four main steps: goal and scope, life cycle inventory (LCI), environmental impacts assessment, and results interpretation. Different studies have carried out the life cycle GHG emission calculations with varying objectives, system boundaries, data sources, and levels of detail, following the LCA methodology $[11,34,35]$. Some studies have briefly evaluated the life cycle $\mathrm{CO}_{2}$ emissions of an HSRS building for energy efficient and carbon reduction analysis [21,22]. However, these previous studies have not analyzed the purpose of evaluating life cycle GHG emissions to extract important design drivers and further understand how to reduce GHG emissions for HSRS buildings. In general, research on life cycle GHG emissions from HSRS buildings is representative, and provides a scientific basis for other large space public buildings.

The need to study the profile of environmental performance of HSRS buildings has led the authors to explore adaptive carbon reduction strategies on low GHG emission design. A typical medium-sized HSRS building in Tianjin, China was selected for the present study as a subject on which to conduct a detailed analysis. This work begins with introducing HSRS in China and outlining significant carbon mitigation measures in general buildings collected from literature, which provide background information about the following analysis. Section 3 presents the methodology used for evaluating and discussing the case study, taking into consideration the life cycle GHG emissions generated from materials and operational energy use. Section 4 describes the case building. The embodied, operational, and total GHG emissions are calculated and results are presented in Section 5 to extract design contributors and deduce reduction-oriented aspects. These findings are further discussed and a stepwise analysis from single to multiple strategies is proposed. The updated results of GHG emissions related to the case with different strategies regarding building space, envelope, and materials are recalculated, and the reduction proportion between origin and updated results of GHG emissions are investigated to extract reduction potentials by comparison. Final remarks are drawn in the conclusions.

\section{Background and Related Studies}

\subsection{HSRS in China}

\subsubsection{Driving Policies and Regulations}

For sustainable development and low carbon transformation, all levels of government (local, province, and even transportation agencies) have adopted effective policies to strengthen response, and taken actions to combat climate change, as illustrated later. A special plan for building energy conservation in China promulgated energy saving renovations at airports, piers, and railway stations according to China's Energy Policy 2012 [36]. The 13th Five-Year Plan (2016-2020) continues to upgrade public buildings to high performance green buildings. Large railway stations are required to optimize design to realize gains in energy efficiency. The China Railway Corporation (CRC) pushed forward energy conservation in railway stations [7] and was required to stimulate a green and low 
carbon transportation plan in accordance with the 13th Five-Year Plan of Railway Development [37]. Newly built railway stations must meet the requirements of the design standard for energy efficiency of public buildings (GB 50189-2015) [38], which indicate that energy consumption of new buildings should be lower than $75 \%$ of that of comparable buildings in the 1980s. The standards for drainage systems, electrical systems, and renewable energy have also been raised [29]. Despite stricter design requirements and improved energy saving standards, there are few systematic design principles, strategies, and applications for reducing the life cycle GHG emissions of HSRS buildings. Under most circumstances, they only rely upon conventional building solutions and experiences of generic buildings and do not consider specific characteristics.

\subsubsection{Characteristics of HSRS Buildings and Climate Zones in China}

Railway stations are classified into super large, large, medium, and small sizes by construction scale, based on the maximum assembling passenger number or dispatched passenger number during rush hour [39]. Medium-sized railway stations are significantly important for study because they have the largest share of the railway station stock in China. A railway station is a complex example of civil engineering, as it includes buildings, platforms, and other infrastructures. In this study, a railway station building refers to the main building in the station, a multi-functional complex that provides facilities such as a waiting room, ticket office, shopping, restaurants, variety stores, and other amenities for passengers. Compared with general public buildings such as governmental offices, domestic HSRS buildings have certain characteristics that are similar to the renewed modern railway stations. Typically, massive, reinforced concrete structures are used with large glass areas and structural steel (see Figure 2). The waiting room/hall is designed as a large enclosed space volume with high floor height making the building a city landmark. Many new stations follow design principles similar to airports, with constant daily operation [20]. For the convenience of management and use, the station building is usually designed along the railway line, so its main orientation is not consistent with the best orientation in most cases.

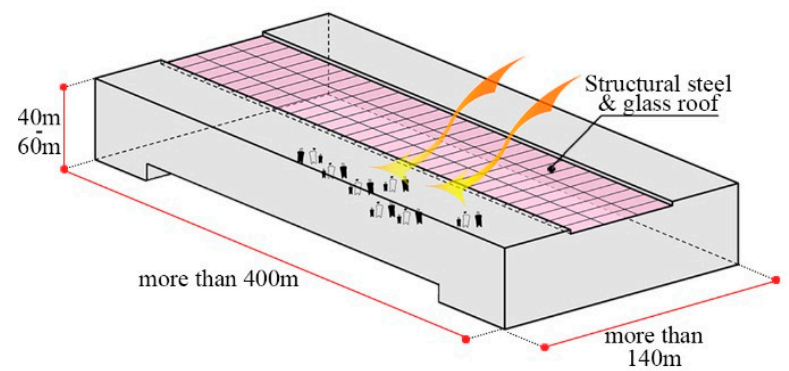

Super-large or large size type

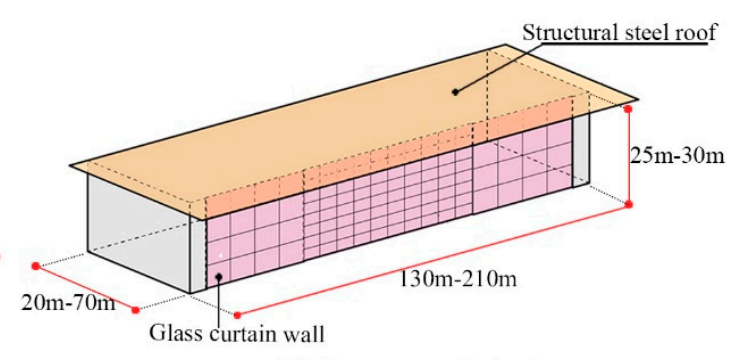

Medium or small size type

Figure 2. Schematic diagram of HSRS building in shape and scale [40].

The local climate conditions to which the building is exposed play a significant role in selecting effective climate responsive strategies during the design process. As defined by the National Uniform Standard for Design of Civil Buildings (GB 50352-2019), China is divided into five main climate zones: severe cold, cold, hot summer and cold winter, hot summer and warm winter, and mild. In northern China, operating energy has a relatively comprehensive configuration in which heating accounts for a larger proportion compared to that in southern regions because of climate condition differences. Severe cold and cold zones in the north region present saving potentials for operational energy emissions on cooling as well as heating. One of the largest cities in the cold zone, Tianjin, has a typical temperate monsoon climate with distinct seasons, which varies greatly in summer (hot and rainy) and winter (cold and dry). The thermal design of the building envelope in Tianjin requires the extensive use of strategies for insulation, not only for the cold winter weather but also for summer heat protection. In this research, a medium-sized building from Tianjin South Railway Station was selected 
as the case to be studied (henceforth Case-TJS). The cold zone and site of the case building are depicted in Figure 3.

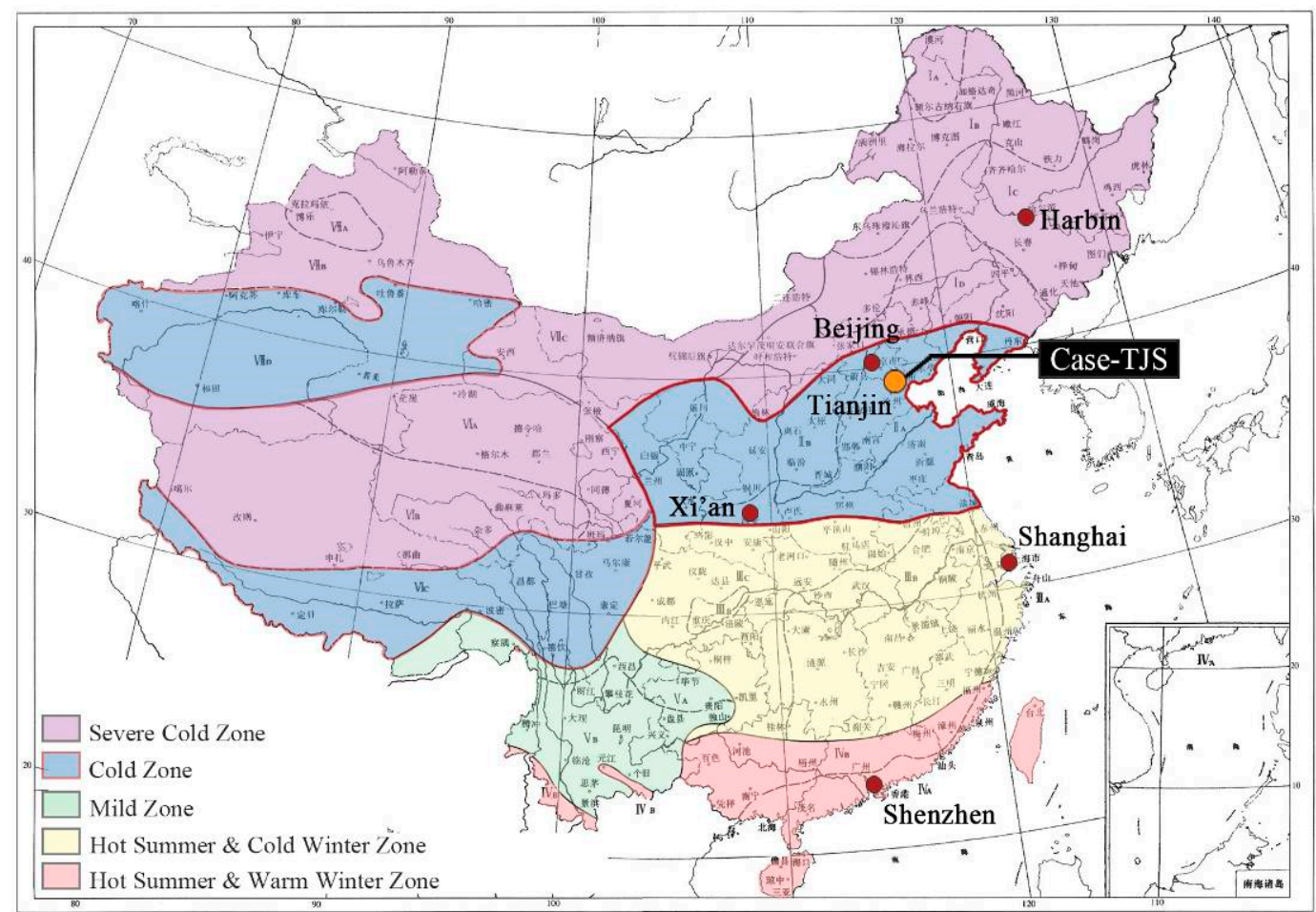

Figure 3. Climatic regionalization map for architecture in China and site of the case study building. (Red spot: representative cities in China, orange spot: Tianjin.).

\subsubsection{Field Investigation and Questionnaire}

To explore the possible influence of design factors on energy consumption, the research team conducted a field investigation of 10 HSRS buildings along the Beijing-Shanghai high-speed railway. The buildings vary in their capacity, GFA, width, depth, and height. A brief comparison is provided in Table 1. It was found that station buildings face the same architectural and technical design problems and have great energy saving potential in terms of form scale, space utilization, function layout, building details, and operating frequency:

- For medium-sized HSRS buildings, the width is usually from $145 \mathrm{~m}$ to $206 \mathrm{~m}$, as well as depth being from 20 to $44 \mathrm{~m}$. The average roof height is approximately $26 \mathrm{~m}$, which is larger in buildings of a super large or large size. There are overcrowded passengers in station (10) but few in station (2), and the capacity design is shown to be not consistent with the scale.

- The height above the enclosed waiting room cannot be used efficiently, since they consume energy for operation, which reflects low utilization of vertical space.

- No thermal partitions are set up in waiting rooms. The HVAC system works for a centralized large room and can't be controlled in a modular way according to the pedestrian volume.

- The glass curtain wall makes the building transparent; however, the shading devices seem not to be enough in summer seasons.

A questionnaire survey was also conducted among 485 passengers on travel behaviour, in which $72 \%$ stated that they prefer to arrive at the waiting room less than half an hour before a train's departure instead of waiting for a long time. In fact, high-speed trains depart every five to ten minutes in most stations, implying that ticket gates have to be opened frequently to check tickets. Passengers do not have to stay in the enclosed waiting room for a long time. The waiting room area, defined originally by 
regulations governing conventional railway stations, encourages unnecessary energy consumption in HSRS.

Table 1. Physical and spatial characteristics of investigated HSRS buildings in the cold zone.

\begin{tabular}{ccccccc}
\hline \multirow{2}{*}{ Code * } & HSRS & $\begin{array}{c}\text { Capacity } \\
\text { (Person) }\end{array}$ & \multirow{2}{*}{$\begin{array}{c}\text { GFA } \\
\left(\mathbf{m}^{\mathbf{2}}\right)\end{array}$} & & \multicolumn{3}{c}{ Space $(\mathbf{m})$} \\
\cline { 5 - 7 } & & & & Width & Depth & Height \\
\hline$(1)$ & Beijing South railway station & 10,500 & 252,000 & 350 & 195 & 40 \\
$(2)$ & Tianjin West railway station & 5000 & 104,000 & 400 & 145 & 57 \\
$(3)$ & Jinan West railway station & 4000 & 100,000 & 192 & 107 & 44 \\
$(4)$ & Langfang railway station & 1000 & 9889 & 170 & 36 & 20 \\
$(5)$ & Tianjin South railway station & 1000 & 8669 & 145 & 20 & 30 \\
$(6)$ & Cangzhou West railway station & 1200 & 10,213 & 168 & 34 & 22 \\
$(7)$ & Dezhou East railway station & 2000 & 19,810 & 206 & 34 & 30 \\
$(8)$ & Qufu East railway station & 1500 & 9996 & 206 & 35 & 28 \\
$(9)$ & Zaozhuang railway station & 1000 & 9965 & 185 & 37 & 21 \\
$(10)$ & Xuzhou East railway station & 2500 & 14,984 & 164 & 44 & 28 \\
\hline$*$
\end{tabular}

* denotes that stations (1)-(3) are super large and large sizes, stations (4)-(10) are medium-sized.

\subsection{GHG Emission Reduction Strategies for Buildings}

Research concentrating on railway station buildings, especially the high speed type, is relatively limited; some of the existing literature takes into account reduction measures for energy consumption that are directly correlated to operational emissions, such as: the relationship between energy consumption and passenger flow density [16]; energy efficiency measures on performance parameters of a building envelope, area ratio of skylight and sun shading mode [17]; energy saving approaches that place greater emphasis on the reduction of air infiltration [18]; triadic relation among lighting comfort level and lighting energy consumption [19]; intelligent control strategies as feasible energy saving solutions [20]; and energy efficient analysis on construction scale, space design, function layout, and operation mode [21,22]. Energy potential in conventional stations or HSRS has been analyzed in different domestic regions. These studies mainly focus on reduction measures in terms of building envelope, while few are concerned with the influence of building form in terms of space design.

In recent years, there has been growing interest in not only the evaluation of embodied emissions, but also the effect of innovative and alternative solutions to reduce total embodied environmental impacts. However, there has been rarely research on railway station buildings focusing on embodied emissions, which can be understood by analyzing other building categories. For instance, Luo et al. [8] analyzed and calculated the $\mathrm{CO}_{2}$ emissions of 78 office buildings in the construction materialization stage, obtaining results of $327 \mathrm{kgCO}_{2} / \mathrm{m}^{2}$ on average (building lifetime is considered to be 50 years). A prediction formula using steel reinforcement, concrete, and wall materials as independent variables was found to predict $\mathrm{CO}_{2}$ emissions. Existing research displayed high carbon mitigation potentials when taking into consideration the substitution of building materials/components during the early stage design of buildings [41]. Zhang et al. [9] demonstrated that residential and office buildings with a reinforced concrete block masonry structure could reduce carbon emissions by $6-18 \%$ compared with either a reinforced or brick concrete structure. Substantial reductions of embodied energy (or carbon) for the use of traditional and locally available building materials were shown, compared to using conventional materials/components in some studies [42,43]. Other studies [44,45] revealed that the use of recycled and reused materials can significantly reduce the embodied energy and carbon emissions in buildings. A study by Maddalena et al. [46] indicated that implementation of materials/components with new and innovative technologies helps reduce the embodied carbon of buildings, such as in the form of "green" types of cements and high performance concrete. 


\section{Methodology}

\subsection{Life Cycle GHG Emissions Calculation}

\subsubsection{Goal and Scope}

The goal of this analysis is to evaluate, quantify, and present an overview of life cycle GHG emissions of the HSRS building as a basis for investigating emission reduction strategies. Figure 4 shows the life cycle phases and system boundary for the case study. The system boundary is founded on the modular life cycle system boundaries as in EN15978: 2011 [31] and defined in accordance with the scope of OM: O (operational energy use), which refers to life cycle module B6, the direct carbon emissions resulting from fossil fuels and electricity during the operation process; $\mathrm{M}$ (materials) corresponds to life cycle modules A1-A3 and B4, for the production and replacement of building materials, the current scope of embodied GHG emission calculation. Embodied GHG emissions are limited from raw material supply to manufacturing of the main products and materials needed, which include material inputs to the gate. The replacement of new materials over the building's lifetime has also been included. A building reference study period is set to 50 years in terms of the design lifetime (50-100 years) of HSRS based on the standard [47]. The estimated service lifespans of different building materials and components are mainly based on average values from product suppliers and research literature $[48,49]$.

The functional unit is expressed as per $1 \mathrm{~m}^{2}$ of unit gross floor area (GFA) over the building lifetime, to provide a reference for relevant inputs and outputs, so as to ensure the comparability of calculation results. The global warming potential (GWP) is weighted by carbon dioxide equivalents $\left(\mathrm{CO}_{2 \text { eq }}\right)$ with the Intergovernmental Panel on Climate Change's 100-year horizon method. Thus, life cycle GHG emissions (noted as $\mathrm{LCCO}_{2 \text { eq }}$ below) $\left(\mathrm{kg} \mathrm{CO}_{2 \mathrm{eq}} / \mathrm{m}^{2} \cdot \mathrm{a}\right)$, GHG emissions per unit construction area and one year of building's service life, can be taken as the functional unit of $\mathrm{LCCO}_{2 \mathrm{eq}}$ of an HSRS building. All the calculations follow the principles of an environmental assessment through life cycle analysis. The calculation model is as follows.

$$
\mathrm{LCCO}_{2 \mathrm{eq}}=\mathrm{LCCO}_{2 \mathrm{eq}}(\mathrm{A} 1-\mathrm{A} 3)+\mathrm{LCCO}_{2 \mathrm{eq}}(\mathrm{B} 4)+\mathrm{LCCO}_{2 \mathrm{eq}}(\mathrm{B} 6)
$$

Here, $\mathrm{LCCO}_{2 \mathrm{eq}}(\mathrm{x})$ refers to the GHG emissions generated from specific $(\mathrm{x})$ life cycle module (A1-A3, B4 or B6). $\mathrm{LCCO}_{2 \text { eq }}$ represents the total GHG emissions of a function unit in the life cycle. In the complete life cycle of an HSRS building, A1-A3, B4, and B6 are together responsible for more than $90 \%$ of total emissions in the case studies [21]. The early design stage has the largest impact on the life cycle stages, while controlling transportation/construction, and the end-of-life stage is difficult [50]. Additionally, energy performance can be improved by architects and engineers by integrating adaptive strategies in the early design stage [51]. Thus, the construction process stage (A4-A5) and end-of-life stage $(\mathrm{C} 1-\mathrm{C} 4)$ have been excluded in this study.

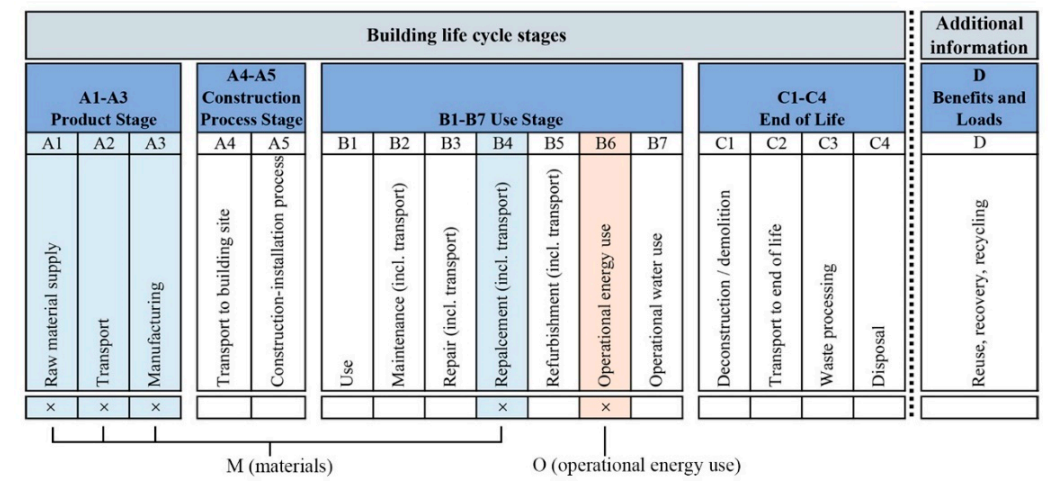

Figure 4. Life cycle phases of a building and system boundary for the case study [31]. 


\subsubsection{Data Sources}

Building materials referred to in this study are mainly categorized into four parts: wall materials, concrete, steel, and mortar. When the case study was carried out, there was an unknown environmental product declaration (EPD) providing transparent and consistent information about specific $\mathrm{CO}_{2 \mathrm{eq}}$ emission data from the construction material supplier or manufacturers in China. Generic $\mathrm{CO}_{2 \mathrm{eq}}$ emission data of construction materials from the Chinese national standard for building carbon emission calculation [52] are used, as shown in Table 2. The $\mathrm{CO}_{2 \text { eq }}$ emission data of construction materials in terms of insulation, window, and concrete block are taken from a database of related research $[48,49]$ when the standard is lacking. Electricity is the only form of energy delivered to the case building systems. The annual electric GHG emission factor plays an important role in operational emission calculation. Previous research has updated the $\mathrm{CO}_{2 \mathrm{eq}}$ factors for Chinese electricity grids in seven regions to determine the organization's and product's carbon footprint with necessary modifications [53]. The present work considers a specific factor of $1.15 \mathrm{kgCO}_{2 \mathrm{eq}} / \mathrm{kWh}$ [53] to calculate the emissions from the electricity, and it is assumed to remain constant during the building's lifetime. The GHG emissions related to energy use can be highly sensitive to the electricity emission factor. The current electricity consumed is from the north region power grid, national public network. The primary energy resources involved come from coal, hydroelectric and wind. Coal-fired electricity generation constitutes approximately $99 \%$ of power generation, leading to a high value of $\mathrm{CO}_{2 \mathrm{eq}}$ factor.

Table 2. $\mathrm{CO}_{2 \text { eq }}$ emission data of partial construction materials in the standard [52].

\begin{tabular}{cccccc}
\hline Material Type & C30 Reinforced Concrete & Steel & Cement & Sand & Stone \\
\hline Unit & $\mathrm{kgCO}_{2 \mathrm{eq}} / \mathrm{m}^{3}$ & $\mathrm{kgCO}_{2 \mathrm{eq}} / \mathrm{t}$ & $\mathrm{kgCO}_{2 \mathrm{eq}} / \mathrm{t}$ & $\mathrm{kgCO}_{2 \mathrm{eq}} / \mathrm{t}$ & $\mathrm{kgCO}_{2 \mathrm{eq}} / \mathrm{t}$ \\
\hline $\mathrm{CO}_{2 \mathrm{eq}}$ Emission Data & 295 & 2340 & 735 & 2.51 & 5.08 \\
\hline
\end{tabular}

\subsubsection{Material Inventories and Levels of Detail}

Load-bearing structures and building envelope partitions are the main sections in the entire building formation stage [8]. Hence, in this study materials inventory is simplified and excludes inventory of building services, equipment, and internal finishes. The life cycle material inventories for the case study are structured according to the building elements classified in the LCA tool, such as groundwork and foundations, load bearing structure, outer walls, inner walls, floor structure, and outer roof. In addition, the construction elements of railway stations outside surroundings such as railway platforms, platform canopies and loading platforms have not been included in the models due to the focus on developing solutions at the individual building level. The data include the most up-to-date building details; material properties and related information were collected from building constructions in order to build a model to obtain the material quantities data. A quota calculation method [54] was chosen to measure the quantities of unclear materials for calculation simplification, such as foundations and steel bars in the concrete structure. A $5 \%$ and $10 \%$ surplus for different materials were added in order to account for on-site processes, broken elements, and purchased quantities.

\subsection{Implementation of Sensitivity Analysis in Building Models}

Sensitivity analysis (SA) is the observational study of identifying the most influential input parameters for the output behaviour in the model. Besides increasing the understanding of the relationships between design parameters and objectives of key performance indicators (KPIs), SA can be a valuable tool for supporting a design-optimization process, by narrowing the search ranges and limiting the number of factors to only the most significant ones. Therefore, it has been broadly used in the domain of building performance analysis and explores the highly sensitive parameters influencing energy performance for design support in various building types or climate zones [55,56]. Two major methods for SA are termed 'local' and 'global' as summarized in [57]. The global sensitivity analysis (GSA), as a more reliable method, includes regression (e.g., SRC), screening methods (e.g., Morris), 
and variance based (e.g., FAST, Sobol indices) and meta-model approaches. When restricted to the quantification of environmental impact, it behaves linearly, with standardized regression coefficients (SRC), etc., that can be chosen [57]. Another technique to avoid extensive combinations of extreme values is stochastic modelling with the aid of a Monte Carlo simulation or Latin hypercube sampling (LHS). In the simulations, a predefined, limited number of combinations of random parameters are used to calculate the outcomes [58].

To simplify the complexity of evaluation, in this study a SA of multiple design variables of building envelope in software to operational GHG emissions was performed to evaluate the highly sensitive parameters. The results are used for preliminary judgment, to predict optimal design strategies, and to conduct further analysis. Design strategies in terms of space and material could not be defined as design variables in aided tools; therefore, the analysis was conducted separately and manually. The SA method implemented in this study is SRC, with the sampling method of LHS. SRC value, as a sensitivity index, is used to describe the relative influence of variability parameters on the output results of a model. A high value of SRC indicates that the parameter has a strong influence on the results. The output objective of 'operational $\mathrm{CO}_{2 \mathrm{eq}}$ emissions' is defined and calculated by referring to annual total energy related emissions.

\subsection{BIM-LCA Approach}

For an efficient and systematic connection of building models, energy simulation, and life cycle GHG calculation, this study integrated all work based on a 'building information model (BIM)' with support tools. The case model, built in Autodesk Revit, contains the building model's geometric, space, and some thermal information; therefore, it is referred to as the 'building information model'. For building energy simulation and further design optimization, the 'building information model' in Autodesk Revit was then converted to the 'building energy model' directly, using simulation software DesignBuilder with EnergyPlus engine. Some complicated and special components should be simplified for making it efficient to run a simulation, but close to the real situations. For instance, beams and columns of structures are deleted and some curves of window corners are changed to straight lines. The energy used for operation of the building was calculated through specific input data for energy simulation. An Excel based LCA tool was used in this study, which was developed by the Research Centre for Zero Emission Buildings and verified in life cycle GHG emission calculations for numerous case studies and pilot buildings $[10,11,59]$. Proper categories and boundaries are set in order to acquire relevant outputs. Quantities of different materials and components have been exported from the Revit/BIM model, and then delivered to the LCA tool for detailed GHG calculations. The materials and components contained in the BIM output correspond to the categories in the LCA tool. In DesignBuilder, GSA of operational energy emissions was also conducted to filter out the highly sensitive parameters, which are the key design strategies of the building envelope to be considered.

\section{Case-TJS}

\subsection{Case Description}

Almost all medium-sized HSRS buildings in the cold zone follow the characteristics mentioned in Section 2.1.2. Additionally, they have a similar structure and envelope pattern and thus the variables are limited. The materials used for the building structure were reinforced concrete, and the envelope is mostly hollow concrete block with a curtain wall system. Case-TJS is used as a representative sample in this study. The results of the analysis are applicable to other medium-sized HSRS buildings in China.

Case-TJS is a 2-story building comprising a ground floor $(0 \mathrm{~F})$ and a first floor (1F, platform), covering a GFA of $8669 \mathrm{~m}^{2}$. It is located in the Xiqing District, southwest of Tianjin, China. The Xiqing district is at $39^{\circ} \mathrm{N}$ latitude with a mean daily outside relative humidity of $62-73 \%$. The mean daily outside air temperature is $29.3^{\circ} \mathrm{C}$ in summer and $-9.4{ }^{\circ} \mathrm{C}$ in winter. The case building is composed of two parts, the west wing building (rail side) and east wing building below the railway lines or 
platform (rail below). Typically, the west wing building is representative in space, structure, envelope, and materials. The internal height is $30 \mathrm{~m}$, the same as the large waiting room. The width and depth are $145 \mathrm{~m}$ and $20 \mathrm{~m}$, respectively. Case-TJS is oriented east west, as are other stations in the Beijing-Shanghai railway network. The maximum assembling passenger number is about 1000 people.

The structural components refer to the column and beams; the foundation and the floor slab are composed of reinforced concrete, others being steel truss structures in the west wing roof. The external walls contain a small concrete hollow block, $100 \mathrm{~mm}$ Rockwool (west wing) or $60 \mathrm{~mm}$ polystyrene (east wing) insulation with an ETERPAN fibre cement board. A double low-E glazing glass curtain wall was used as a waiting hall envelope. The outer roof of the west wing consists of $100 \mathrm{~mm}$ of aluminium foil glass wool insulation with colour steel lamellas for the sunscreen. The east wing roof is mainly covered with a reinforced concrete slab and $80 \mathrm{~mm}$ extruded polystyrene (XPS) insulation. No skylights and solar thermal collectors are currently installed on the roof. The floor is decking with $30 \mathrm{~mm}$ of XPS insulation, fine stone concrete, and granite.

\subsection{Parameter Setting for Simulation}

Figure 5a shows the building information model built in Autodesk Revit. Figure 5b shows the building energy model in the simulation software DesignBuilder. The meteorological data used for the simulation correspond to the local climate, according to the Chinese Standard Weather Data. Heated rooms, such as the waiting hall and office, are the primary areas with floor heating and XPS insulation. The indoor design parameters of occupancy, the HVAC system, lighting, and domestic hot water (DHW) are in accordance with the real condition and code for design of a railway passenger station [39], and are shown in Table 3. The waiting hall/room is a typical feature in station buildings; the parameter in these areas is particularly important. The occupancy density of the waiting hall is determined as 0.12 persons $/ \mathrm{m}^{2}$ considering the high mobility and regularity of passengers. To achieve satisfactory levels of thermal comfort in summer, most railway stations in cold regions have a central air conditioning system. Electric power is needed for energy supply solutions. The building has a balanced mechanical ventilation system equipped with a heat recovery unit. The variable air volume ventilation operates a mixed flow in the waiting and ticket room: the fresh air is supplied into the building from the top and is extracted down into devices below. Standard hygienic flow rates are imposed, with minimum fresh air $2.778 \mathrm{l} / \mathrm{s}$ per person. The building is equipped with electric water to the water/ground source heat pump (GSHP) to cover the thermal needs (i.e. space heating and cooling). A floor heating system is used in the waiting room. The value of the whole system seasonal coefficient of performance (SCOP) in heating and the energy efficiency ratio (SEER) in cooling for specific pump power is set to 4.0 and 4.8 respectively. The heat pump produces hot water with a temperature of $45^{\circ} \mathrm{C}$ in winter, and cold water combined with air-to-water chillers in summer (supply temperature of $12{ }^{\circ} \mathrm{C}$ ). The energy consumption of fans, pumps and other auxiliary equipment is calculated. The consumption rate of $0.4 \mathrm{l} / \mathrm{m}^{2}$.day is supplied for DHW with a draw-off temperature set at $65^{\circ} \mathrm{C}$. These reflect the practices in modern medium-sized HSRS buildings. The operation schedule is from 05:00 to 23:00, in keeping with the existing train time of day scheduling in Case-TJS. The indoor illuminance of the waiting room is controlled to be 200 lux and the power density is $8 \mathrm{~W} / \mathrm{m}^{2}$. 


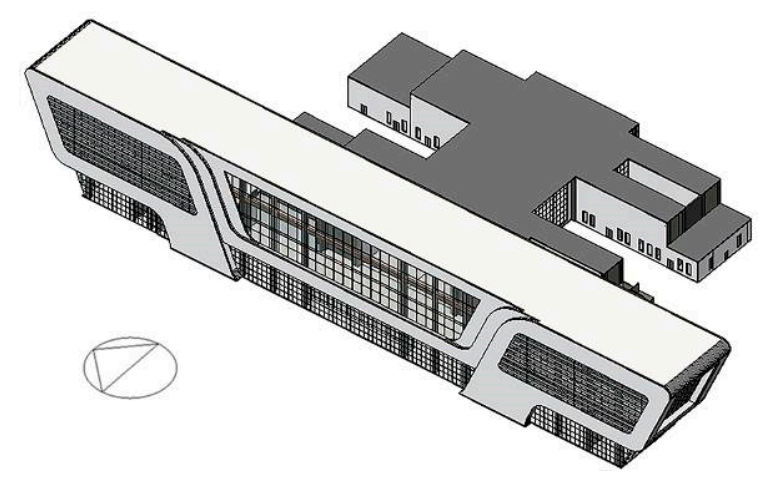

(a)

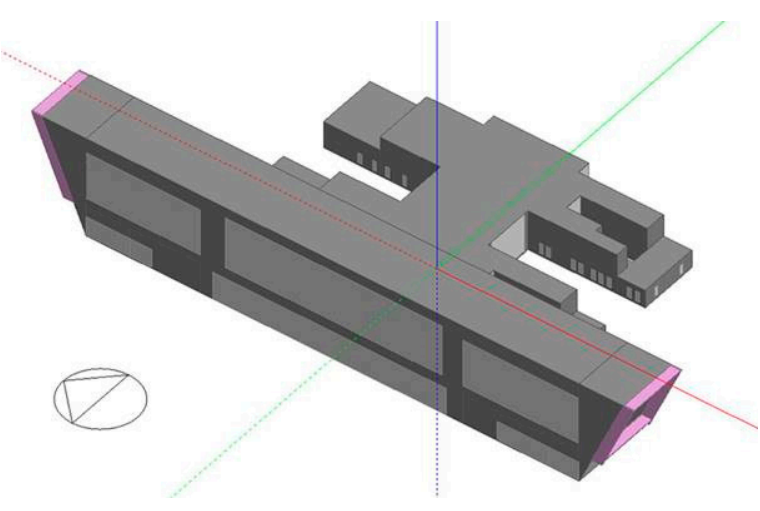

(b)

Figure 5. (a) Bird's eye view of building information model (BIM) in Revit; (b) Building energy model in DesignBuilder.

Table 3. Design parameters for the occupancy, HVAC system, lighting, and DHW.

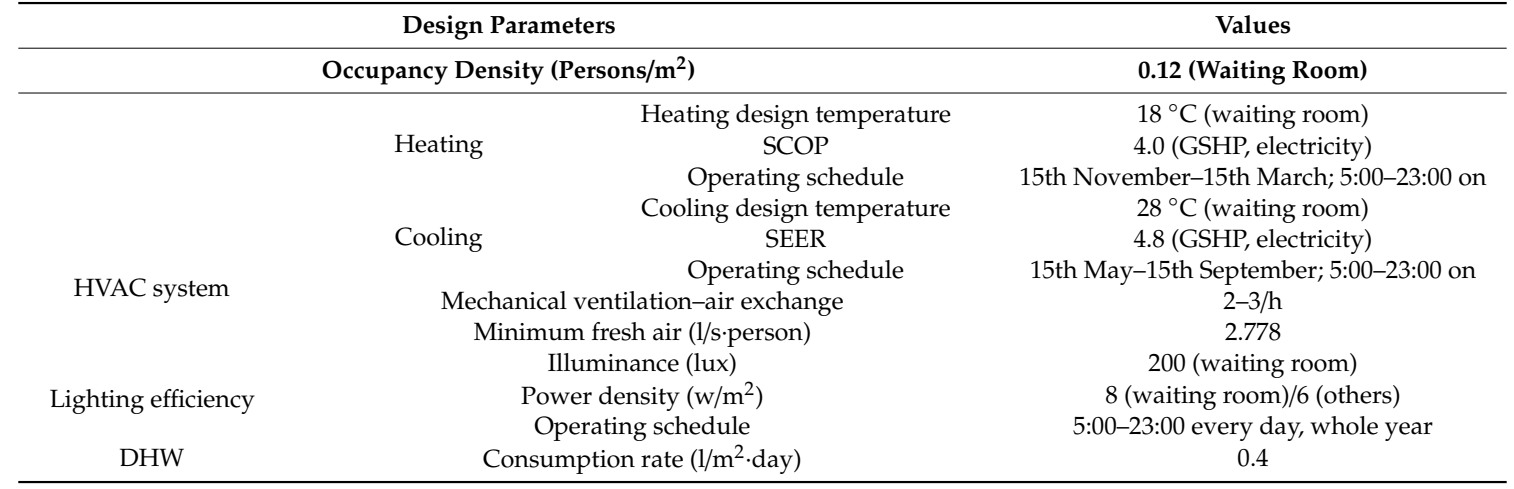

\section{Results and Discussion}

\section{1. $\mathrm{LCCO}_{2 e q}$ by Life Cycle Module}

According to energy simulation results shown in Figure 6, the total annual electricity consumption for the building is 706,523 kWh/year, including heating, cooling, lighting, fans and pumps, and DHW. The operation energy use per unit area of the case building is $81.5 \mathrm{kWh} / \mathrm{m}^{2} \cdot \mathrm{a}$, corresponding to operational energy emissions of $94 \mathrm{kgCO}_{2 \mathrm{eq}} / \mathrm{m}^{2} \cdot \mathrm{a}$, as electric $\mathrm{CO}_{2 \mathrm{eq}}$ factor is $1.15 \mathrm{kgCO}$ eq $/ \mathrm{kWh}$. Heating and cooling are the main energy consumers in Case-TJS, followed by lighting, which is consistent with the previous study about large-sized HSRS buildings [22].

Figure 7 shows the contribution of different life cycle modules in GHG emissions, assuming a 50-year life span. The total $\mathrm{LCCO}_{2 \mathrm{eq}}$ is calculated to be $115 \mathrm{kgCO}_{2 \mathrm{eq}} / \mathrm{m}^{2} \cdot \mathrm{a}$. The majority of emissions apparently occur during the operational energy use phase $(\mathrm{O}$, or $\mathrm{B} 6)$, constituting a percentage of $81 \%$. Thus, operational energy emissions are much more dominant than embodied GHG emissions for the case study. This can mainly be due of the high emission factor used for the grid. As a previous analysis shows, low utilization of vertical height is perhaps also a reason for not only high energy consumption and associated emissions in domestic HSRS buildings, but also low occupant density of the waiting room. Construction material emissions from the production and replacement phases (A1-A3 and B4) contribute $14.1 \%$ and $4.7 \%$ respectively, with a high level of $22 \mathrm{kgCO}_{2 \mathrm{eq}} / \mathrm{m}^{2} \cdot \mathrm{a}$ in total, compared to other building typologies. The embodied GHG emissions of life cycle module A1-A3 is 3.0 times that of module B4. The calculation results also highlight the significance of embodied GHG emissions, accounting for approximately 19\% of GHG emissions generated from the life cycle of HSRS buildings. 


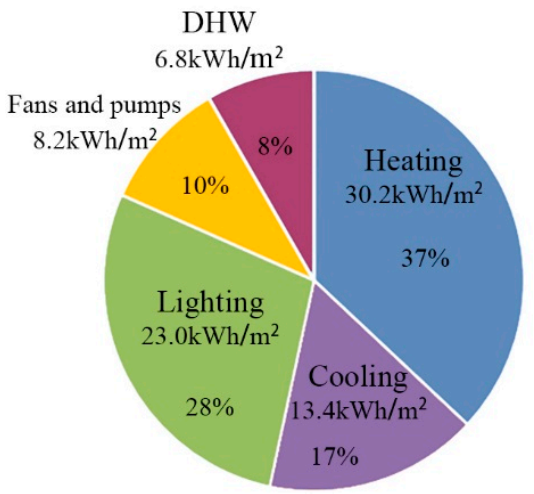

Figure 6. Distribution of annual operational energy use $\left(\mathrm{kWh} / \mathrm{m}^{2} \cdot \mathrm{a}\right)$.

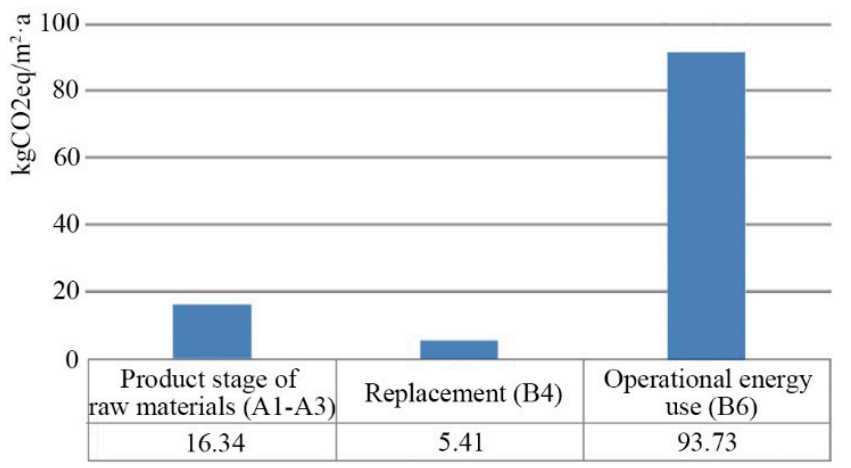

Figure 7. GHG emissions per life cycle module $\left(\mathrm{kgCO}_{2 \mathrm{eq}} / \mathrm{m}^{2} \cdot \mathrm{a}\right)$.

\subsection{Embodied GHG Emissions of Building Materials}

\subsubsection{Embodied GHG Emissions by Building Elements}

This study detailed the embodied GHG emissions of each section in life cycle modules A1-A3 and B4. The embodied GHG emissions of different building elements and the percentage they constitute are summarized in Table 4 . The results show that outer walls are the largest contributor to high embodied GHG emissions across the building elements, contributing approximately $48 \%$ to total embodied GHG emissions; the load bearing structure contributes approximately $26 \%$; the floor structure and outer roof contribute approximately $10 \%$ equally; while groundwork, foundations, and inner walls contribute the least. A breakdown of embodied GHG emissions by each building element is shown in Figure 8. Outer walls and load-bearing structures are main drivers for high embodied GHG emissions because they constitute the main construction elements of the building and use materials with high embodied GHG emissions such as reinforced concrete and steel.

Table 4. GHG emissions per building element and the proportion that they constitute.

\begin{tabular}{|c|c|c|c|c|c|c|}
\hline & \multicolumn{2}{|c|}{ Life Cycle Module A1-A3 } & \multicolumn{2}{|c|}{ Life Cycle Module B4 } & \multicolumn{2}{|c|}{ Life Cycle Module A1-A3, B4 } \\
\hline & $\begin{array}{l}\mathrm{CO}_{2 \mathrm{eq}} \text { Emissions } \\
\left(\mathrm{kgCO}_{2 \mathrm{eq}} / \mathrm{m}^{2} \cdot \mathrm{a}\right)\end{array}$ & $\begin{array}{l}\text { Percentage } \\
(\%)\end{array}$ & $\begin{array}{c}\mathrm{CO}_{2 \mathrm{eq}} \text { Emissions } \\
\left(\mathrm{kgCO}_{2 \mathrm{eq}} / \mathrm{m}^{2} \cdot \mathrm{a}\right)\end{array}$ & $\begin{array}{l}\text { Percentage } \\
(\%)\end{array}$ & $\begin{array}{l}\mathrm{CO}_{2 \mathrm{eq}} \text { Emissions } \\
\left(\mathrm{kgCO}_{2 \mathrm{eq}} / \mathrm{m}^{2} \cdot \mathrm{a}\right)\end{array}$ & $\begin{array}{c}\text { Percentage } \\
(\%)\end{array}$ \\
\hline $\begin{array}{l}\text { Groundwork, } \\
\text { foundations }\end{array}$ & 0.58 & 3.56 & 0 & 0 & 0.58 & 2.67 \\
\hline Load bearing structure & 5.65 & 34.61 & 0 & 0 & 5.65 & 25.98 \\
\hline Outer walls & 6.19 & 37.92 & 4.17 & 77.13 & 10.37 & 47.68 \\
\hline Inner walls & 0.60 & 3.69 & 0 & 0 & 0.60 & 2.76 \\
\hline Floor structure & 1.68 & 10.29 & 0.47 & 8.77 & 2.16 & 9.93 \\
\hline Outer roof & 1.62 & 9.92 & 0.76 & 14.10 & 2.38 & 10.94 \\
\hline Total & 16.34 & 100 & 5.41 & 100 & 21.75 & 100 \\
\hline
\end{tabular}




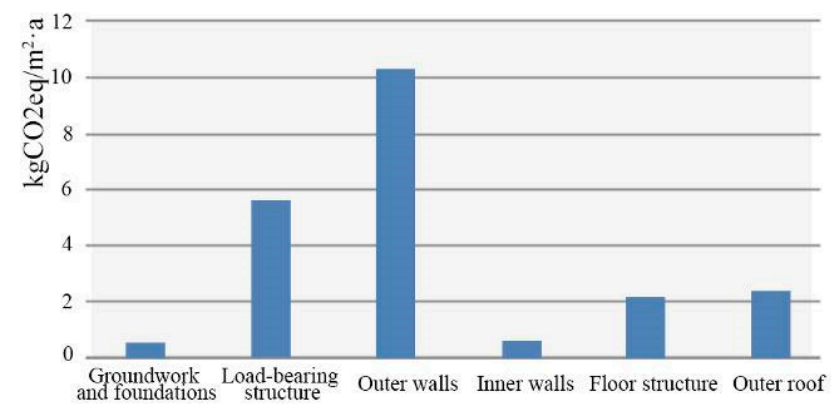

Figure 8. Comparison of embodied GHG emissions by building elements.

\subsubsection{Embodied GHG Emissions by Construction Materials}

Figure 9 shows the embodied GHG emissions by major construction materials. The blue histogram represents emission results from material production phases (A1-A3) of each material and the proportion they constitute out of all the materials, while the orange histogram represents emission results from the material replacement phase (B4). By analyzing the blue histogram, the highest GHG emissions are generated from three types of construction materials-concrete, steel, and insulation materials-contributing nearly $71 \%$ totally to GHG emissions of material production. Of these emissions, more than half (ca. 52\% total) are generated from concrete and steel materials, which are the design drivers. For an HSRS building, a large waiting room space means a large span and greater height. The former requires higher structural strength and will lead to high use of steel material from steel roof and reinforced concrete structure, such as load bearing (architectural beam and column). The concrete consumption will increase to support the greater height as well.

However, when comparing the GHG emissions that belong to material replacement (see orange histogram in Figure 9), a big difference in trend can be found, as follows: the high GHG emissions of material replacement are mainly from three types of construction materials-insulation material, windows, and plaster-among which insulation material is the design driver. This distribution is caused by the lower service life of these materials: 25 years. Thus, during the buildings' 50-year life span, insulation materials, windows, and plaster are required to be replaced once. If comparing the total embodied GHG emissions (A1-A3, B4), the insulation emission would be much greater than that of other materials.

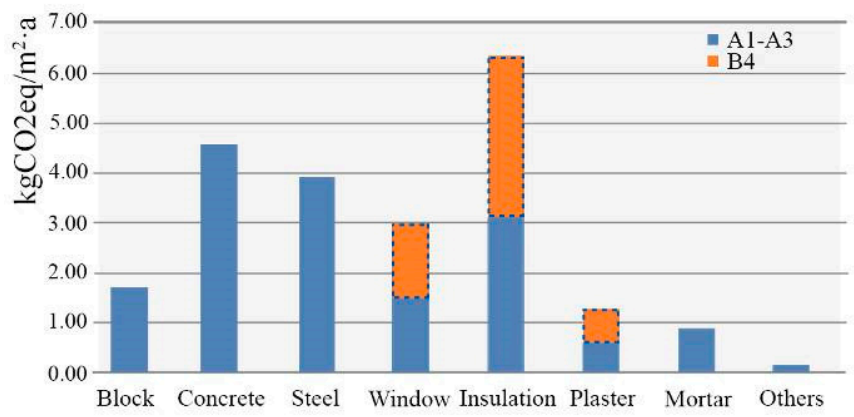

Figure 9. Level of material inventory detail and comparison of embodied GHG emissions.

\subsection{Reduction Strategies of Life Cycle GHG Emissions}

The case originally aimed at evaluating $\mathrm{LCCO}_{2 \mathrm{eq}}$ to extract design drivers and influences. It is believed that high emissions are affected by three aspects of buildings: space, envelope, and materials. Due to stringent energy requirements of design standard and energy efficiency improvement [38], the reduction possibilities in operational energy emissions by means of an energy system are obvious. The building energy consumption of the case study, indeed, is lower compared to that of other conventional railway station buildings [20], mainly due to the usage of the high performance system 
heat pump. However, in this article, the main attention has been paid to the building performance at the design level (or, passive strategies) rather than service systems such as HVAC. A building envelope-especially outer wall, roof, and glass curtain wall-has an impact on the energy performance of buildings and the main building elements for GHG calculation. Therefore, for an HSRS building as specific typology, reduction possibilities and potentials of $\mathrm{LCCO}_{2 \mathrm{eq}}$ should be identified on building space, building envelope, and material, as the scope of design strategies.

\subsubsection{Reduction Strategies of Operational GHG Emissions}

\section{Optimizing Building Space}

The space of Case-TJS was optimized in two ways: changing the height and area of the waiting room. The height of the west wing building was reduced from $30 \mathrm{~m}, 25 \mathrm{~m}$, to $20 \mathrm{~m}$, itemized as strategy $\mathrm{H}_{1}, \mathrm{H}_{2}$, and $\mathrm{H}_{3}$, respectively. The operational GHG emissions decrease by $15.7 \%$ and total $\mathrm{LCCO}_{2 \mathrm{eq}}$ decreases by $15.0 \%$ from strategy $\mathrm{H}_{1}$ to $\mathrm{H}_{3}$. Embodied GHG emissions decrease by up to $12.3 \%$ and see a significant reduction. This is because, with the decline of the building height, the enclosed volume to use energy for heating and cooling is reduced. Meanwhile, fewer materials of outer walls and the load bearing structure are consumed. The area of the waiting room was reduced from $2346 \mathrm{~m}^{2}$, $1313 \mathrm{~m}^{2}$, to $657 \mathrm{~m}^{2}$ through functional adjustment, itemized as strategy $\mathrm{A}_{1}, \mathrm{~A}_{2}$, and $\mathrm{A}_{3}$, respectively. It also resulted in more enclosed space being opened without heating and cooling for passengers going through the building to the platform in half an hour. Due to the fact that the area of the waiting room is determined by the maximum number of passengers $(\mathrm{H})$, this change assumed that $0 \% \mathrm{H}, 36 \% \mathrm{H}$, and $72 \% \mathrm{H}$ can check in directly, while others remain in the enclosed waiting room. Although embodied GHG emissions remain unchanged, the operational GHG emissions decrease greatly, by up to $24.8 \%$, leading to a decrease in the total GHG emissions by $20.1 \%$.

\section{Optimizing Building Envelope}

The design variables are quantified using a computational tool, combining options into 256 samples $(4 \times 4 \times 4 \times 4)$. From the SA results shown in Table 5, it can be determined that the glazing type has the most correlative influence on operational GHG emissions, with the largest SRC value, followed by external walls and outer roof constructions. By linear regression analysis results together with SA, deterministic coefficient adjusted $R^{2}$ of regression equation reaches 0.97 , which indicates that there is a strong linear relationship between design variables and operational GHG emissions. After correlation and regression analysis, glazing type was selected as an optimal design variable of envelope to make changes for emission reduction. The double low-E glazing type of curtain walls $(8+12 \mathrm{Air}+8)$ and windows $(6+9$ Air +6$)$ was changed in the case building to double low-E coated glazing $(6+12$ Air +6$)$ and double low-E insulated glazing $(6+12$ Argon +6$)$, with different specific parameters (U-value, Solar Heat Gain Coefficient-SHGC), itemized as strategy $\mathrm{U}_{\mathrm{G} 1}, \mathrm{U}_{\mathrm{G} 2}$, and $\mathrm{U}_{\mathrm{G} 3}$. As a result, the impacts decrease by $7.7 \%$ during the operational phase from strategy $\mathrm{U}_{\mathrm{G} 1}$ to $\mathrm{U}_{\mathrm{G} 3}$ because of the change with high performance and low emissivity materials. Embodied GHG emissions decrease by $6.8 \%$. In addition, an optimal solution is taken from the samples simultaneously (see Table 5), which could be used in the comprehensive comparison of different optimization scenarios with multiple strategies. 
Table 5. Design variables matrix for SA, SRC values, and optimal solution.

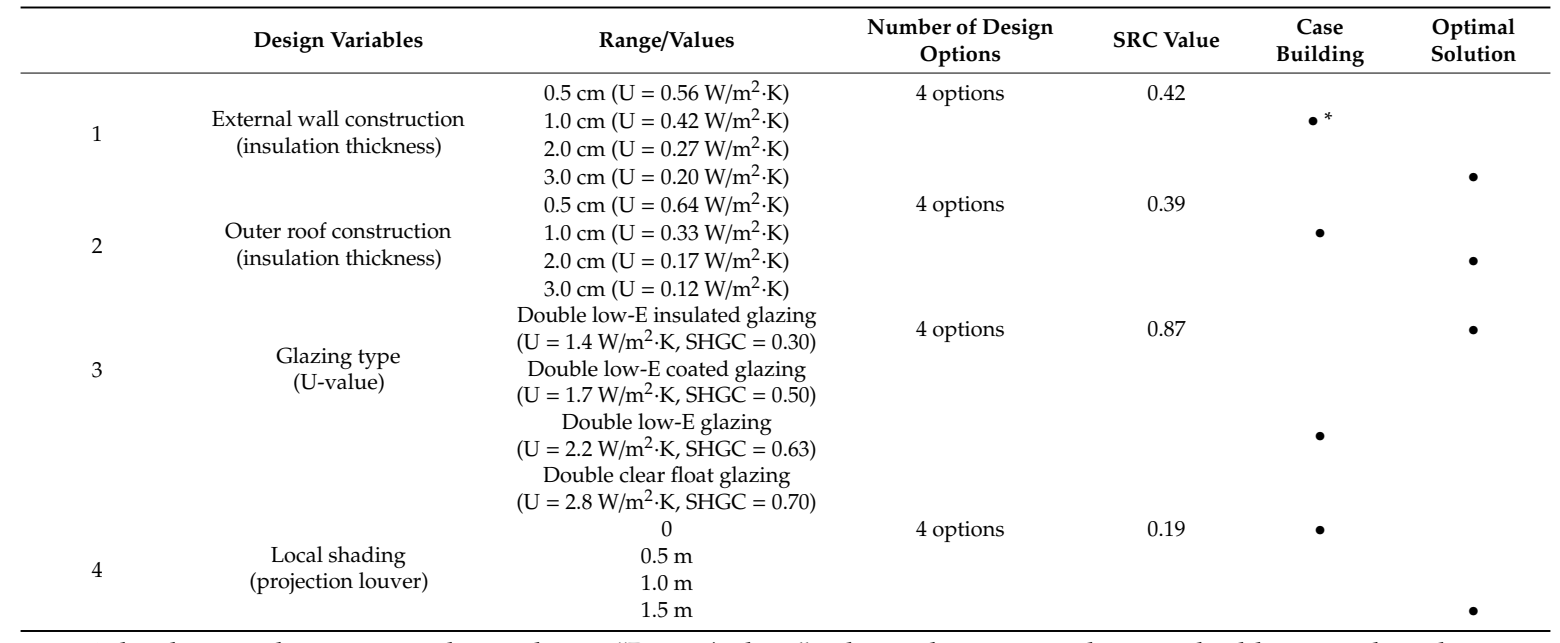

* dot denotes the corresponding value in "Range/values" column that was used in case building or selected in optimal solution.

\subsubsection{Reduction Strategies of Embodied Emissions}

Construction materials could be optimized with regard to embodied emissions, by alternative building design and material solutions. In life cycle GHG calculations, it is assumed that material alternatives only change emission data or the service life of materials, while technical properties such as load bearing capacity and thermal performance remain the same as before.

\section{Substitution of Construction Materials}

The above analysis reveals that concrete and steel are the main contributors for embodied GHG emissions from materials. No recycled or reused materials are used in reality, itemized as strategy $S_{1}$ for comparison. In reduction strategies, low embodied carbon materials are chosen. As a reference, railway stations can be evaluated at a good level in material utilization if the percentage weight of recycled and reused materials is more than $20 \%$ of that of total construction materials [60]. To reach the $20 \%$ target, recycled aggregate concrete and recycled steel were substituted for $30 \%$ of reinforced concrete and structural steel in the case building, itemized as strategy $\mathrm{S}_{3}$. It represents the weight of recycled aggregate concrete and recycled steel, constituting $20 \%$ of the total amount of concrete and steel. In addition, 15\% of reinforced concrete and structural steel were substituted by recycled aggregate concrete and recycled steel, itemized as strategy $S_{2}$. Incorporating the recycled concrete and steel in calculations can help reduce embodied GHG emission impacts arising from materials, although there is little influence on total GHG emissions (a $0.7 \%$ reduction).

\section{Service Life Extension of Insulation Material}

Maximizing the use of materials can reduce the number of times replacements are required during building operation; therefore, it has a great effect on replacement. The service life of insulation increased from 25 years to 35 years and 50 years compared to the case building, itemized as strategy $E_{1}, E_{2}$, and $E_{3}$. The result reveals that embodied GHG emissions greatly decrease up to $15 \%$, while total GHG emissions reduce by $2.8 \%$ after extending the service life of materials from 25 years to 50 years. Single strategies optimized in the case building and GHG emissions are presented in Table 6 and the histogram given in Figure 10. 
Table 6. Single strategies optimized in the case building and GHG emissions $\left(\mathrm{kgCO}_{2 \mathrm{eq}} / \mathrm{m}^{2} \cdot \mathrm{a}\right)$.

\begin{tabular}{|c|c|c|c|c|c|}
\hline \multirow{2}{*}{ Single Strategies } & \multicolumn{3}{|c|}{ Embodied GHG Emissions } & \multirow{2}{*}{$\begin{array}{c}\text { Operational } \\
\text { GHG Emissions }\end{array}$} & \multirow{2}{*}{$\begin{array}{c}\text { Total Life Cycle GHG } \\
\text { Emissions }\end{array}$} \\
\hline & Module A1-A3 & Module B4 & Total Modules & & \\
\hline $\begin{array}{c}\text { Case building }\left(\mathrm{H}_{1} / \mathrm{A}_{1} / \mathrm{U}_{\mathrm{G} 1} / \mathrm{S}_{1} /\right. \\
\left.\mathrm{E}_{1}\right)\end{array}$ & 16.34 & 5.41 & 21.75 & 93.73 & 115.48 \\
\hline $\mathrm{H}_{2}=25 \mathrm{~m}$ & 15.58 & 5.06 & 20.64 & 83.54 & 104.18 \\
\hline $\mathrm{H}_{3}=20 \mathrm{~m}$ & 14.63 & 4.45 & 19.08 & 78.98 & 98.06 \\
\hline Reduction $(\%) *$ & $-10.5 \%$ & $-17.7 \%$ & $-12.3 \%$ & $-15.7 \%$ & $-15.0 \%$ \\
\hline Reduction $(\%) *$ & - & - & - & $-24.8 \%$ & $-20.1 \%$ \\
\hline $\mathrm{U}_{\mathrm{G} 2}=1.7 \mathrm{~W} / \mathrm{m}^{2} \cdot \mathrm{K}$ & 15.79 & 4.86 & 20.65 & 90.15 & 110.80 \\
\hline $\mathrm{U}_{\mathrm{G} 3}=1.4 \mathrm{~W} / \mathrm{m}^{2} \cdot \mathrm{K}$ & 15.60 & 4.67 & 20.27 & 86.51 & 106.78 \\
\hline Reduction $(\%) *$ & $-4.5 \%$ & $-13.6 \%$ & $-6.8 \%$ & $-7.7 \%$ & $-7.5 \%$ \\
\hline$S_{2}=15 \%$ recycled concrete + steel & 15.93 & 5.41 & 21.34 & 93.73 & 115.07 \\
\hline$S_{3}=30 \%$ recycled concrete + steel & 15.52 & 5.41 & 20.93 & 93.73 & 114.66 \\
\hline
\end{tabular}

* denotes the GHG emissions reduction (\%) of building optimized by single strategies $\left(\mathrm{H}_{3}, \mathrm{~A}_{3}, \mathrm{U}_{\mathrm{G}}, \mathrm{S}_{3}, \mathrm{E}_{3}\right)$ compared to the reference $\left(\mathrm{H}_{1}, \mathrm{~A}_{1}, \mathrm{U}_{\mathrm{G} 1}, \mathrm{~S}_{1}, \mathrm{E}_{1}\right)$ in each column.

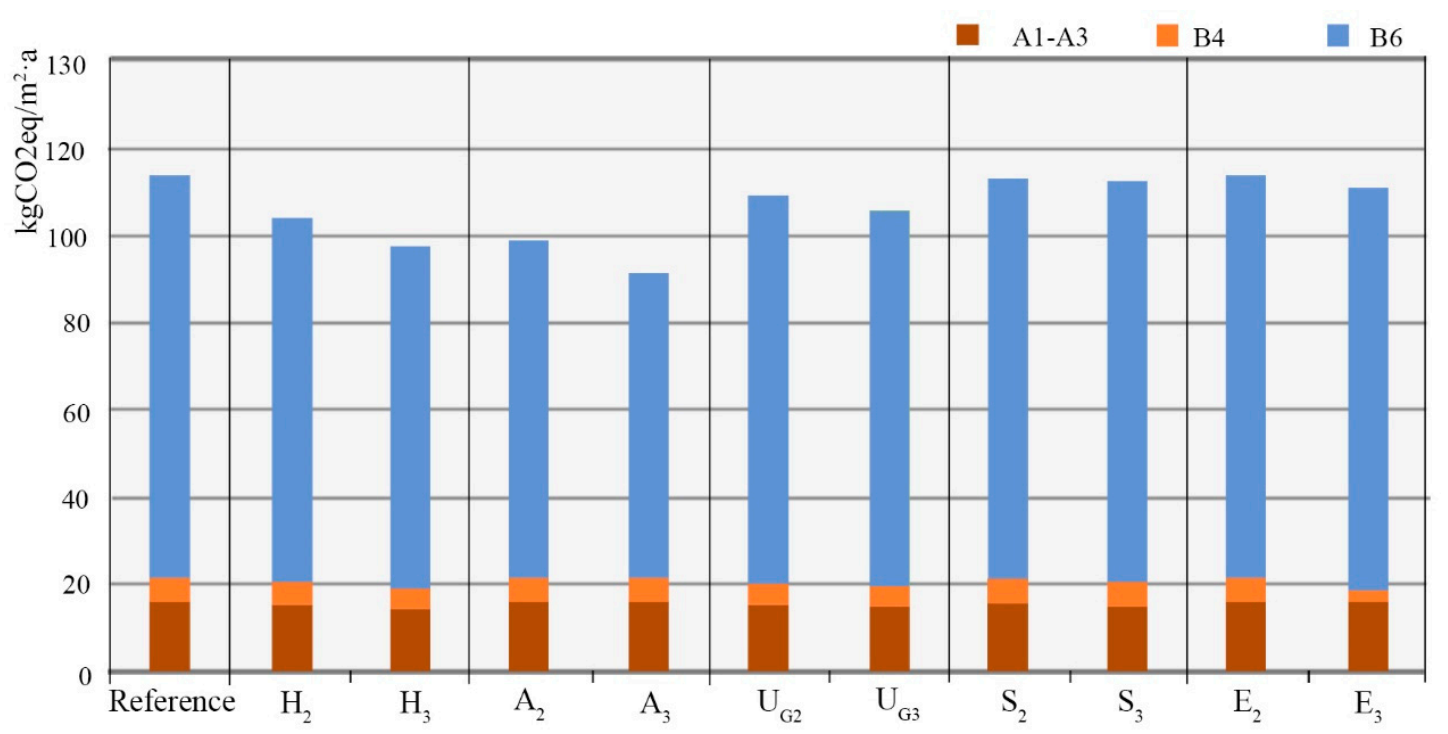

Figure 10. GHG emissions of case building with different single strategies.

\subsubsection{Reduction Potential Analysis of Life Cycle GHG Emissions}

In order to evaluate the reduction potential comprehensively, three optimization scenarios with multiple strategies were proposed under new simulation and calculation: space, envelope, and material optimization. Space optimization corresponds with the optimal single strategy such as $\mathrm{H}_{3}$ and $\mathrm{A}_{3}$ that were integrated in the case. Envelope optimization corresponds to an optimal solution in Table 5 that was integrated in the case. Optimal single strategy $\mathrm{S}_{3}$ and $\mathrm{E}_{3}$ were integrated as material optimization. Figure 11 shows the annual operation energy use in all three scenarios. In scenario 1 , the operational energy use of the case building was reduced to $50-60 \mathrm{kWh} / \mathrm{m}^{2} \cdot \mathrm{a}$, which is close to the median value in offices or schools shown in Figure 1. A comparison was made between the total GHG emission results of optimization scenarios, as summarized in Table 7. Taking the origin case as a reference, it can be seen that space optimization has the greatest reduction potential of total GHG emissions, with a reduction percentage of $28.2 \%$. There are fewer changes relatively in total GHG emissions under material optimization, but it contributes to a 3.5\% reduction. In this study, if these three optimizations are all integrated into the case with model adjustments and updated parameters, the total GHG emissions will decrease up to $33.8 \%$ after recalculation. 


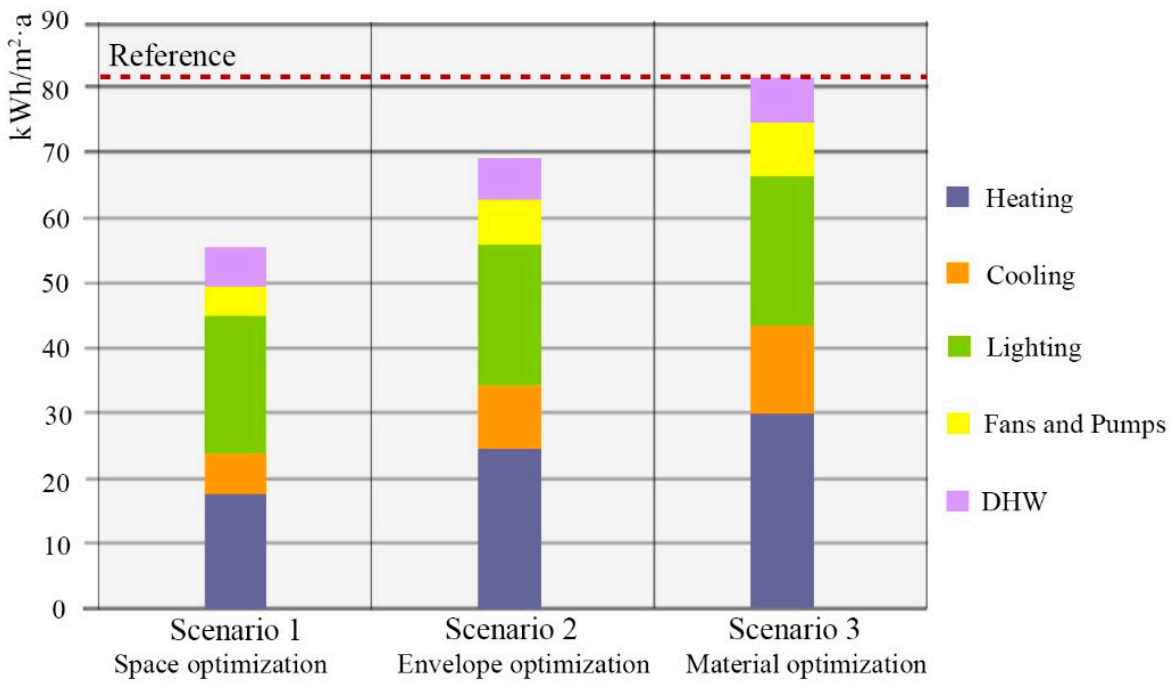

Figure 11. Annual operation energy use in all three scenarios $\left(\mathrm{kWh} / \mathrm{m}^{2} \cdot \mathrm{a}\right)$.

Table 7. Summary of the life cycle GHG emission results of different optimization scenarios $\left(\mathrm{kgCO}_{2 \mathrm{eq}} / \mathrm{m}^{2} \cdot \mathrm{a}\right)$.

\begin{tabular}{cccc}
\hline & $\begin{array}{c}\text { Space Optimization } \\
\mathbf{( H}_{\mathbf{3}}, \mathbf{A}_{\mathbf{3}} \text { in Table 1) }\end{array}$ & $\begin{array}{c}\text { Envelope Optimization } \\
(\text { Optimal Solution in Table 1) }\end{array}$ & $\begin{array}{c}\text { Material Optimization } \\
\left(\mathbf{S}_{3}, \mathbf{E}_{\mathbf{3}} \text { in Table 1) }\right.\end{array}$ \\
\hline A1-A3 & 14.63 & 15.60 & 15.52 \\
B4 & 4.45 & 4.67 & 2.15 \\
B6 & 63.80 & 80.01 & 93.73 \\
Embodied GHG emissions & 19.08 & 20.27 & 17.67 \\
Total GHG emissions & 82.88 & 100.28 & 111.4 \\
Reduction (\%) & $-28.2 \%$ & $-13.1 \%$ & $-3.5 \%$ \\
\hline
\end{tabular}

* denotes the reduction value (\%) of total GHG emissions in optimization scenarios compared to the reference value $\left(115 \mathrm{kgCO}_{2 \mathrm{eq}} / \mathrm{m}^{2} \cdot \mathrm{a}\right)$.

There are key reductions in operational GHG emissions when space form varies, indicating that optimizing building space has great potential for reducing energy associated GHG emissions, especially by reducing the area of enclosed waiting rooms. Improving the waiting behaviour of passengers is significant for emission reduction on the assumption that more passengers can check in directly. The result is consistent with the previous study [61], which indicates the key link between the operation phase and emissions reduction for similar large space public buildings such as museum buildings in China. Compared with a Swedish HSRS building [27], the result is reversed: construction and maintenance are more dominant in GHG emissions, while operation gives just a small contribution as a result of used green electric power. Therefore, it is meaningful to study HSRS buildings in different regions.

It should be noticed that the linear relationship between operational GHG emissions and area is not evident, as investigated in [16] the regarding correlation between energy consumption and station area. In energy simulations of this study, energy use from the waiting room accounts approximately for $60 \%$ of total energy consumption from all operating rooms. Although the energy use of the waiting room could greatly decrease, the energy consumed in other rooms including the booking hall, offices and commercials remains unchanged. Lighting and DHW constitute $36 \%$ in annual operational energy use, but they are not sensible when waiting room area changes are a necessary service for passengers in semi-open areas. This is why operational GHG emissions reduce only by $24 \%$ when the area of the waiting room reduces drastically from $2346 \mathrm{~m}^{2}$ to $657 \mathrm{~m}^{2}$ by $72 \%$.

Another focus should be on using low emissivity and high performance materials/components, e.g., glazing type. In terms of embodied GHG emission reduction, extending the service life of insulation material contributes the most, followed by optimizing space. Using recycled concrete and 
steel has a relatively minimal impact. In practice, recycled materials are usually insufficient and the amount for substitution is limited. In order to minimize embodied GHG emissions, efforts should be made to choose robust insulation materials (i.e. longer service life) and to reduce the amount of materials. Recycled concrete and steel with low emissions could also be used to make contributions more or less.

In three scenarios, space optimization can greatly reduce operational as well as embodied GHG emissions, indicating the significance of space design in emission reduction during the architectural design process. The reduction potential of total GHG emissions from envelope optimization comes from the performance improvement in terms of thermal properties and low emissivity. However, this improvement is limited because newly built HSRS buildings have up to or over the required standard values on envelope [38], whereas stricter performance costs more. Generally, compared to the innovative incorporation of state-of-the-art materials and technology to drive down emissions relating to the operational phase, the process of space optimization in buildings is deemed time saving and is economically applicable.

As life cycle GHG emissions calculations are developed, the robustness of these results against uncertainties should be noticed. The choice of electricity grid factor has a large influence on operational GHG emissions. If assuming factor value of the current grid of $0.361 \mathrm{kgCO}_{2 \mathrm{eq}} / \mathrm{kWh}$ in the EU [62], the operational GHG emissions could be close to the embodied GHG emissions. The future studies should test different scenarios with the decarbonization of the electricity grid over building lifespan. The life cycle analysis presented in this study also involves a number of simplifications and generalisations. The emission factors of construction materials use generic data from standard and research databases, although these factors may vary in a specific practice. The construction materials have been limited to civil engineering excluding building services. Results are therefore discussed for these specific contexts. Although simplified, this framework of analysis is nevertheless representative for most of the medium-sized HSRS buildings in the cold zone.

The proposed BIM-LCA method connects LCA with BIM and comprehensively applies different software for study systematically, however, there are some limitations. Although the simulation software DesignBuilder has improved abilities to analyze the Revit models, some incompatibility problems occur, especially when the model is established in a more complex way. Non-linear geometric primitives should be simplified. For the Case-TJS, most of the origin components in the Revit model have been imported into Designbuilder for smoother energy analysis, which plays a positive role in the BIM-LCA method.

\section{Conclusions}

Previous research usually does not pay sufficient attention to HSRS buildings from the direct perspective of life cycle GHG emissions and how to reduce GHG emissions. Therefore, this article set out to evaluate and present the life cycle GHG emissions $\left(\mathrm{LCCO}_{2 \mathrm{eq}}\right)$ of an HSRS building in a cold zone, China to extract the design drivers in terms of operational and embodied GHG emissions. Design drivers and reduction strategies were examined in order to assess their potential as strategies for reduced GHG emissions from a functional and architectural point of view. This paper proposed a detailed methodology for the development and assessment of emission reduction strategies through LCA, combined with BIM technology. The Case-TJS, a medium-sized HSRS building, was selected as a representative example for a case study. This study comes to the following conclusions:

(1) Emission reduction measures in an HSRS building should focus more on space design in the early stage of architectural design. Although the GHG emission mitigation strategy related to the substitution of materials presents the lowest potential for total GHG emissions reduction, significant embodied emission reduction can be achieved by choosing insulation materials with longer service life.

(2) The $\mathrm{LCCO}_{2 \text { eq }}$ of an HSRS building for design analysis were assessed using 3 system boundaries: life cycle modules A1-A3 and B4 for the production and replacement of building materials, and 
life cycle module B6 for operational energy use. The BIM-LCA approach shows how modelling tools help analysis identify in GHG reduction strategies in complex buildings such as HSRS.

(3) The main objective of the GHG reduction strategies in HSRS buildings is to minimize the total GHG emissions related to operational energy and, ultimately, the embodied emissions from materials.

(4) The drivers for the highest embodied GHG emissions were from concrete, steel, and insulation materials used in the main load bearing structures and outer wall components.

In summary, this paper contributes to research by identifying strategies to reducing GHG emissions with a focus on the HSRS building typology which is a particular type of large space public building in China. It is anticipated that the research results that might significantly reduce GHG emissions in HSRS buildings would have a positive impact on the mitigation of current climate change effects. The results for GHG emissions and reduction strategies also provide guidance to help inform design and construction decisions of similar projects and large space public buildings.

Author Contributions: Conceptualization, N.W.; methodology, N.W.; validation, N.W. and D.S.; formal analysis, N.W.; investigation, N.W.; resources, C.L., A.H.W. and D.S.; writing-original draft preparation, N.W.; writing-review and editing, D.S., C.L. and A.G.; visualization, N.W.; supervision, A.H.W., C.L. and A.G.; project administration, C.L. and A.G.; and funding acquisition, C.L. All authors have read and agreed to the published version of the manuscript.

Funding: This research was funded by the National Key Research and Development Program of China (Grant No. 2016YFC0700200), National Natural Science Foundation of China (Grant No. 51808383), and the Programme of Introducing Talents of Discipline to Universities (project No. B13011).

Acknowledgments: The authors would like to thank the China Scholarship Council (CSC) for providing financial support to carry out the cooperation study. The authors gratefully acknowledge the support from the Research Council of Norway and several partners through the Research Centre on Zero Emission Neighbourhoods in Smart Cities (FME ZEN), hosted by the Norwegian University of Science and Technology (NTNU).

Conflicts of Interest: The authors declare no conflict of interest.

\section{References}

1. International Energy Agency and the United Nations Environment Programme. Global Status Report 2018: Towards a Zero-Emission, Efficient and Resilient Buildings and Construction Sector; International Energy Agency and the United Nations Environment Programme: Katowice, Poland, 2018; Available online: https://www.unenvironment.org/resources/report/global-status-report-2018 (accessed on 15 September 2019).

2. Department of Climate Change, National Development and Reform Commission of China. Enhanced Actions on Climate Change; China's Intended Nationally Determined Contributions (INDC): Beijing, China, 2015.

3. State Council of China. 13th Five-Year Plan of Energy Saving and Emission Reduction. Available online: http://www.gov.cn/zhengce/content/2017-01/05/content_5156789.htm (accessed on 20 September 2019).

4. Building Energy Efficiency Centre, Tsinghua University. Annual Report on Development of China Building Energy Efficiency; China Architecture and Building Press: Beijing, China, 2019.

5. Wang, H.; Zhou, P.; Guo, C.; Tang, X.; Xue, Y.; Huang, C. On the calculation of heat migration in thermally stratified environment of large space building with sidewall nozzle air-supply. Build. Environ. 2019, 147, 221-230. [CrossRef]

6. Building Energy Efficiency Centre, Tsinghua University. Annual Report on Development of China Building Energy Efficiency; China Architecture and Building Press: Beijing, China, 2014.

7. National Development and Reform Commission of China. The Mid-Long Term Planning for China's Railway Network (2016-2025); National Development and Reform Commission of China: Beijing, China, 2016.

8. Luo, Z.; Yang, L.; Liu, J. Embodied carbon emissions of office building: A case study of China's 78 office buildings. Build. Environ. 2016, 95, 365-371. [CrossRef]

9. Zhang, X.; Wang, F. Life-cycle assessment and control measures for carbon emissions of typical buildings in China. Build. Environ. 2015, 86, 89-97. [CrossRef]

10. The Research Centre on Zero Emission Buildings (ZEB), Zero Emission Buildings, NTNU and SINTEF; Fagbokforlaget: Bergen, Norway, 2017. 
11. Wiik, M.K.; Fufa, S.M.; Kristjansdottir, T.; Andresen, I. Lessons learnt from embodied GHG emission calculations in zero emission buildings (ZEBs) from the Norwegian ZEB research centre. Energy Build. 2018, 165, 25-34. [CrossRef]

12. Rodríguez Serrano, A.Á.; Porras Álvarez, S. Life Cycle Assessment in Building: A Case Study on the Energy and Emissions Impact Related to the Choice of Housing Typologies and Construction Process in Spain. Sustainability 2016, 8, 287. [CrossRef]

13. Amirkhani, S.; Bahadori-Jahromi, A.; Mylona, A.; Godfrey, P.; Cook, D. Impact of Low-E Window Films on Energy Consumption and $\mathrm{CO}_{2}$ Emissions of an Existing UK Hotel Building. Sustainability 2019, 11, 4265. [CrossRef]

14. French, J. SusStations Project. In Proceedings of the 7th International Conference on. Improving, Energy Efficiency in Commercial Buildings (IEECB), Frankfurt, Germany, 18-19 April 2012.

15. Indian Green Building Council (IGBC), IGBC Green Railway Stations. Available online: https://igbc.in/igbc/ redirectHtml.htm?redVal=showGreenRailwaynosign (accessed on 5 October 2019).

16. Song, L.; Wang, Y.; Li, X. Energy performance and environmental quality of typical railway passenger stations in northern China. Indoor Built Environ. 2018, 27, 296-307. [CrossRef]

17. Yang, X.E. Building energy efficiency design for waiting halls of railway stations in the hot summer and cold-winter region. J. Eng. Sci. Technol. Rev. 2017, 10, 1-7. [CrossRef]

18. Yang, L.; Xia, J. Case study of space cooling and heating energy demand of a high-speed railway station in China. Procedia Eng. 2015, 121, 1887-1893. [CrossRef]

19. Gang, L.; Yi, X.; Rui, D.; Chen, L. The research of triadic relation among building spaces, lighting comfort level and lighting energy consumption in high-speed railway station in China. Procedia Eng. 2015, 121, 854-865. [CrossRef]

20. Asian Development Bank. Improving Energy Efficiency and Reducing Emissions through Intelligent Railway Station Buildings; Asian Development Bank: Mandaluyong, Philippines, 2015.

21. Wang, N.; Wang, J.L.; Liu, C.H.; Liu, L. Energy-Saving Potential of Large Space Public Buildings Based on BIM: A Case Study of the Building in High-Speed Railway Station. In eWork and eBusiness in Architecture, Engineering and Construction; Karlshoj, J., Scherer, R., Eds.; CRC Press: Copenhagen, Denmark, 2019. [CrossRef]

22. Wang, J.; Wang, N.; Liu, L.; Liu, C. Energy-efficient analysis of high-speed railway station design in the cold region: A case study on Tianjin West Railway Station. Eco-City Green Build 2018, 9, 44-51. (In Chinese)

23. Li, Q.; Yoshino, H.; Mochida, A.; Meng, Q.; Lei, B.; Zhao, L.; Lun, Y. CFD study of the thermal environment in an air-conditioned train station building. Build. Environ. 2009, 44, 1452-1465. [CrossRef]

24. Deb, C.; Ramachandraiah, A. Evaluation of thermal comfort in a rail terminal location in India. Build. Environ. 2010, 45, 2571-2580. [CrossRef]

25. Chow, W.K.; Fung, W.Y.; Wong, L.T. Preliminary studies on a new method for assessing ventilation in large spaces. Build. Environ. 2002, 37, 145-152. [CrossRef]

26. Chong, U.; Swanson, J.J.; Boies, A.M. Air quality evaluation of London Paddington train station. Environ. Res. Lett. 2015, 10, 1-11. [CrossRef]

27. Stripple, H.; Uppenberg, S. Life-Cycle Assessment of Railways and Rail Transport-Appplication in Environmental Product Declarations (EPDs) for the Bothnia Line; Swedish Environmental Research Institute: Göteborg, Sweden, 2010; Available online: https://www.ivl.se/download/18.343dc99d14e8bb0f58b75d4/1445517456715/B1943.pdf (accessed on 3 February 2020).

28. Zhang, R.; Liu, P.; Zhou, C.C.; Amorelli, A.; Li, Z. Configuration of inter-city high-speed passenger transport infrastructure with minimal construction and operational energy consumption: A superstructure based modelling and optimization framework. Comput. Chem. Eng. 2016, 93, 87-100. [CrossRef]

29. Ma, J.J.; Du, G.; Zhang, Z.K.; Wang, P.X.; Xie, B.C. Life cycle analysis of energy consumption and $\mathrm{CO}_{2}$ emissions from a typical large office building in Tianjin, China. Build. Environ. 2017, 117, 36-48. [CrossRef]

30. Skaar, C.; Labonnote, N.; Gradeci, K. From Zero Emission Buildings (ZEB) to Zero Emission Neighbourhoods (ZEN): A Mapping Review of Algorithm-Based LCA. Sustainability 2018, 10, 2405. [CrossRef]

31. EN 15978. Sustainability of Construction Works-Assessment of Environmental Performance of Buildings-Calculation Method; European Committee for Standardization: Brussels, Belgium, 2011.

32. ISO 14040. Environmental Management_Life Cycle Assessment_Principles and Framework; International Organization for Standardization: Geneva, Switzerland, 2006. 
33. ISO 14044. Environmental Management_Life Cycle Assessment_Requirements and Guidelines; International Organization for Standardization: Geneva, Switzerland, 2006.

34. Selamawit, F.; Schlanbudch, R.; Sørnes, K.; Inman, M.; Andresen, I. A Norwegian ZEB Definition Guideline; The Reserch Centre on Zero Emission Buildings (ZEB), ZEB Project Report (29) SINTEF; Academic Press: Oslo, Norway, 2016.

35. Dokka, T.H.; Sartori, I.; Thyholt, M.; Lien, K.; Lindberg, K.B. A Norwegian Zero Emission Building Definition; Passihus Norden: Gothenburg, Sweden, 2013.

36. Information Office of the State Council, China's Energy Policy 2012 (White Paper); Information Office of the State Council: Beijing, China, 2012.

37. National Development and Reform Commission of China. 13th Five-Year Plan of Railway Development; National Development and Reform Commission of China: Beijing, China, 2017.

38. Ministry of Housing and Urban-Rural Development of China, GB 50189-2015: Design Standard for Energy Efficiency of Public Buildings; China Architecture and Building Press: Beijing, China, 2015.

39. National Railway Administration. TB10100-2018 Code for Design of Railway Passenger Station; National Railway Administration: Beijing, China, 2018.

40. Wang, J.; Liu, C. Investigation and analysis of energy-efficient potential to the space and form of high-speed railway station building. Build. Energy Effic. 2019, 2, 41-49. (In Chinese)

41. Malmqvist, T.; Nehasilova, M.; Moncaster, A.; Birgisdottir, H.; Nygaard, F. Design and construction strategies for reducing embodied impacts from buildings-Case study analysis. Energy Build. 2018, 166, 35-47. [CrossRef]

42. Yu, D.; Tan, H.; Ruan, Y. A future bamboo-structure residential building prototype in China: Life cycle assessment of energy use and carbon emission. Energy Build. 2011, 43, 2638-2646. [CrossRef]

43. Venkatarama Reddy, B.V.; Leuzinger, G.; Sreeram, V.S. Low embodied energy cement stabilised rammed earth building. Energy Build. 2014, 68, 541-546. [CrossRef]

44. Kumanayake, R.; Luo, H.; Paulusz, N. Assessment of material related embodied carbon of an office building in Sri Lanka. Energy Build. 2018, 166, 250-257. [CrossRef]

45. Seo, S.; Zelezna, J.; Birgisdottir, H. Passer, A. Evaluation of Embodied Energy and CO2eq for Building Construction (Annex 57); Institute for Building Environment and Energy Conservation: Tokyo, Japan, 2016; Available online: http://www.iea-ebc.org/Data/publications/EBC_Annex_57_ST2_Literature_Review.pdf (accessed on 5 October 2019).

46. Maddalena, R.; Roberts, J.J.; Hamilton, A. Can Portland cement be replaced by low-carbon alternative materials? A study on the thermal properties and carbon emissions of innovative cements. J. Clean. Prod. 2018, 186, 933-942. [CrossRef]

47. Ministry of Housing and Urban-Rural Development of China. GB 50352-2019. Uniform Standard for Design of Civil Buildings; Ministry of Housing and Urban-Rural Development of China: Beijing, China, 2019.

48. Zhang, X. Research on the Quantitative Analysis of Building Carbon Emissions and Assessment Methods for Low-carbon Buildings and Structures; Harbin Institute of Technology: Harbin, China, 2018. (In Chinese)

49. Luo, Z. Study on Calculation Method of Building Life Cycle CO2 Emission and Emission Reduction Strategies; Xi'an University of Architecture and Technology: Xi'an, China, 2016. (In Chinese)

50. Roh, S.; Tae, S. Building Simplified Life $\mathrm{Cycle} \mathrm{CO}_{2}$ Emissions Assessment Tool (B-SCAT) to Support Low-Carbon Building Design in South Korea. Sustainability 2016, 8, 567. [CrossRef]

51. Raji, B.; Tenpierik, M.J.; Van den Dobbelsteen, A. Early-Stage Design Considerations for the Energy-Efficiency of High-Rise Office Buildings. Sustainability 2017, 9, 623. [CrossRef]

52. Ministry of Housing and Urban-Rural Development of the People's Republic of China. GB/T 51366-2019 Standard for Building Carbon Emission Calculation; Ministry of Housing and Urban-Rural Development of the People's Republic of China: Beijing, China, 2019.

53. Hou, P.; Wang, H.T.; Zhang, H.; Fan, C.D.; Huang, N. GreenHouse gas emission factors of Chinese power grids for organization and product carbon footprint, Zhongguo Huanjing Kexue. China Environ. Sci. 2012, 32, 961-967. (In Chinese)

54. Standard Quota Institute. TY01-31-2015 Consumption Quota of Housing Construction and Decoration Engineering; China Planning Press: Beijing, China, 2015. (In Chinese)

55. Zhao, M.; Künzel, H.M.; Antretter, F. Parameters influencing the energy performance of residential buildings in different Chinese climate zones. Energy Build. 2015, 96, 64-75. [CrossRef] 
56. Mechri, H.E.; Capozzoli, A.; Corrado, V. USE of the ANOVA approach for sensitive building energy design. Appl. Energy 2010, 87, 3073-3083. [CrossRef]

57. Groen, E.A.; Bokkers, E.A.M.; Heijungs, R.; de Boer, I.J.M. Methods for global sensitivity analysis in life cycle assessment. Int. J. Life Cycle Assess. 2017, 22, 1125-1137. [CrossRef]

58. Budavari, Z.; Szalay, Z.; Brown, N.; Malmqvist, T.; Peuportier, B.; Zabalza, I.; Krigsvoll, G.; Wetzel, C.; Cai, X.; Staller, H.; et al. LoRE-LCA-Deliverable 5.2 Methods and Guidelines for Sensitivity Analysis, Including Results for Analysis on Case Studies; SINTEF: Trondheim, Norway, 2011; Available online: https://www.sintef.no/ globalassets/project/lore-lca/deliverables/lore-lca-wp5-d5.2-emi_final.pdf (accessed on 20 October 2019).

59. ZEB Tool Manual. Technical Guide. Version 1, The Research Centre for Zero Emission Buildings; Internal Memo: Trondheim, Norway, 2017.

60. National Railway Administration. TB/T 10429-2014: Evaluation Standard for Green Railway Stations; National Railway Administration: Beijing, China, 2014.

61. Cheng, B.; Li, J.; Tam, V.W.Y.; Yang, M.; Chen, D. A BIM-LCA Approach for Estimating the Greenhouse Gas Emissions of Large-Scale Public Buildings: A Case Study. Sustainability 2020, 12, 685. [CrossRef]

62. Graabak, I.; Bakken, B.H.; Feilberg, N. Zero emission building and conversion factors between electricity consumption and emissions of greenhouse gases in a long term perspective. Environ. Clin. Technol. 2014, 13, 12-19. [CrossRef]

(C) 2020 by the authors. Licensee MDPI, Basel, Switzerland. This article is an open access article distributed under the terms and conditions of the Creative Commons Attribution (CC BY) license (http://creativecommons.org/licenses/by/4.0/). 